\title{
A Fully-Automated Environmental Chamber for Examination of Long-Term Effects of Intermittent Hypoxia on Medium-Size Animals
}

\author{
Xavier CHAUfOUR, Faiq ISSA, Colin SULLIVAN, Craig MCLACHLAN, and Gunnar UNGER \\ Department of Medicine, University of Sydney, Sydney, NSW, Australia
}

\begin{abstract}
Summary: We describe the design and construction of a fully-automated environmental chamber for the simultaneous exposure of up to four medium-size laboratory animals to long-term intermittent hypoxia. The air-sealed automated environmental chamber consists of a box equipped with a ventilation fan and three electrically-activated solenoid valves. Our system was used to expose four rabbits to $12 \mathrm{~h}$ of repetitive episodes of hypoxia (environmental $\mathrm{O}_{2}$ concentration $12-13 \%$ ) lasting $45 \mathrm{~min}$ followed by
\end{abstract}

breathing room air for 15 min. During environmental hypoxia, the mean arterial $\mathrm{Pa}_{\mathrm{O}_{2}}$ and $\mathrm{Pa}_{\mathrm{CO}_{2}}$ were $41 \pm 3.0$ and $24 \pm 0.7 \mathrm{mmHg}$ (mean \pm SEM), respectively. In this system, opening and closing of the solenoid valves is fully computerized to allow different settings of the duration and severity of hypoxia. The chamber is safe and fully automated and cost-effective for studying the effects of long-term intermittent hypoxemia in medium-size animals. [Japanese Journal of Physiology, 49, 207-211, 1999]

Key words: intermittent hypoxia, induction, methods, laboratory animals.

The role of hypoxia in tissue injury is well established. More importantly, intermittent hypoxia has been recently recognized to induce a more severe form of tissue injury due to the associated changes in tissue perfusion before, during and after hypoxia. In neural tissues, intermittent hypoxia and reoxygenation cause brain injury due to the release of superoxide free radicals and excitatory amino acids $[1,2]$.

Several studies have examined the role of intermittent hypoxia on organ physiology and pathophysiology in diseases affecting a variety of organs/systems such as the cardiovascular system [3, 4], muscles [5] and central nervous system $[6,7]$. In the majority of these studies, the rat was used as the experimental animal model. The selection of rats in these studies is based on several factors including ease of handling, housing and the ability to expose more than one rat to hypoxia and/or other test conditions. These criteria usually facilitate research and allow acquisition of data within a relatively short period of time. On the other hand, medium-size animals, such as rabbits and piglets, have also been used in similar studies $[8,9]$, but to our knowledge, no report has previously described a fully-automated method that allows simultaneous acquisition of data from more than one medium-size animal during exposure to a hypoxic environment.

We designed a fully-automated chamber that allows the simultaneous exposure of four rabbits to long-term intermittent hypoxia. We describe, in this communication, the design and construction of the chamber.

The chamber box allows simultaneous housing of four rabbits (2-3 kg body weight) for monitoring cardiorespiratory function and behavior over several weeks or months. The chamber was designed taking into consideration the minimum area requirements for housing laboratory rabbits $\left(1,400-3,600 \mathrm{~cm}^{2}\right)$. The size of the chamber is $1,200 \mathrm{~W} \times 500 \mathrm{D} \times 600 \mathrm{H} \mathrm{mm}$ with a total volume of $360 \mathrm{l}$. The chamber is constructed of wood except for the front plexiglass door. The door is attached to the body of the chamber by four hinges. To provide an airtight seal, a self-adhesive foam tape is used around the entire edge of the door and the frame of the chamber, together with sev- 


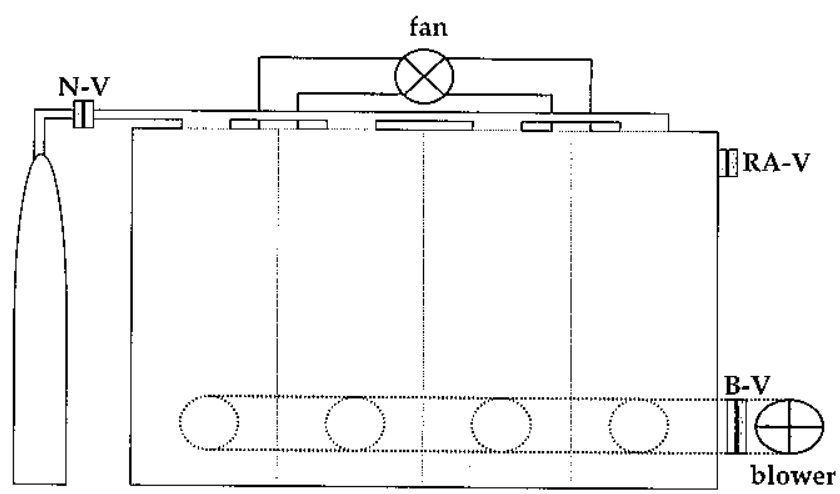

Fig. 1. Schematic diagram of the environmental chamber used in the present study. $B-V$, valve in series with the blower/suction motor; RA- $V_{1}$ solenoid valve that controls entry of room air into the environmental chamber; $\mathrm{N}-\mathrm{V}$, valve that controls entry of $\mathrm{N}_{2}$ into the chamber; $\mathrm{N}_{2}$, nitrogen cylinder; blower, blower/suction pump; Fan, ventilation fan. Note the four compartments for housing up to four animals. $\mathrm{N}_{2}$ gas is delivered into the chamber through four inlets for quick distribution and mixing. The blower/suction motor is connected to the chamber via four conduit pipes for easy equilibrium of gas-mixture in all four compartments.

eral other large screw-type locks. Ventilation is provided by an exhaust fan fitted into a conduit pipe (ID: $100 \mathrm{~mm}$ ) placed outside the chamber (Fig. 1). The fan also maintains a stable environmental temperature within the chamber. Both the inlet and outlet of the pipe housing the fan are covered with a fine-screen mesh to prevent suction of dust, hair or other material.

The chamber is divided into four equal compartments by sliding walls constructed of grill-type steel mesh. These walls allow easy distribution of air or gas mixtures through all four compartments. The three partitions separating the four animals are designed to fit through a mounting frame. A similar material is used underneath each animal, below which a tray is placed to collect urine and excreta. Appropriate food and water containers are placed on the partition walls. The chamber is placed on a table slightly tilted to the left rear corner so excess urine can drain easily through a pipe into a container placed underneath the table.

The chamber is housed in an air-conditioned room $\left(23 \pm 1^{\circ} \mathrm{C}\right)$. In this environment, the interior temperature varies from 24 to $26^{\circ} \mathrm{C}$ when four animals are housed inside the chamber. Once the animals are inside the chamber and the door is closed, the exhaust fan is continuously turned on to allow ventilation. The chamber is also fitted with a large solenoid valve, which is open to atmosphere at the power-off position (see below) in order to prevent an increase in humidity and accumulation of $\mathrm{CO}_{2}$. Circulation of air is also assisted by a large capacity $(650 \mathrm{l} / \mathrm{min})$ digitally-controlled blower-suction motor (model 800, Hitachi, Tokyo) that allows suction of room air into the chamber (see below).

The concentrations of $\mathrm{O}_{2}$ and $\mathrm{CO}_{2}$ inside the chamber were measured continuously by using an Oxymeter (Normocap Oxy, Datex Engstrom, Helsinki, Finland) through a plastic tube inserted inside the box. The level of environmental $\mathrm{O}_{2}$ concentration can be manipulated by a series of digitallycontrolled electronic solenoid valves (Fig. 1). Using the hardware/software described in this report, the operator selects the duration of the hypoxic cycle (from room air to the desired $\mathrm{O}_{2}$ concentration to room air), duration of hypoxia within the cycle, the level of hypoxia and the duration of exposure to room air. This is performed by setting different parameters, using custom-made software, that set the time of power ON/OFF of one or more valves and the delay time to power-on of the other valves. Once the duration of each cycle is selected, the computer-controlled system can run continuously throughout the day or until the experiment is terminated manually.

Three electronic valves are used in the system. (1) A $25.4 \mathrm{~mm}$ orifice valve (SCD210857, Ascomation, Sydney, Australia) is used to control the flow of $\mathrm{N}_{2}$ gas into the chamber. The input of this valve (Fig. 1, $\mathrm{N}-\mathrm{V}$ ) is connected to a large cylinder filled with pure $\mathrm{N}_{2}$ gas, while the output is connected to a $25 \mathrm{~mm}$ conduit tube that distributes $\mathrm{N}_{2}$ into the chamber through four separate pipes feeding into each of the four different compartments. The $\mathrm{N}$-valve is normally closed and activation opens the valve to allow passage of $\mathrm{N}_{2}$ into the chamber. (2) Another $25.4 \mathrm{~mm}$ orifice blower valve (SCD210857, Ascomation) controls the ventilation and circulation of air within the chamber. This valve (Fig. 1, B-V) is normally closed, and when activated, it allows the suction/blower motor to circulate the gas mixture through the four compartments. (3) A $32 \mathrm{~mm}$ orifice ambient air valve (SCD282D22, Ascomation) is connected directly to a hole drilled into the chamber and the valve is in open position when inactivated. This valve (Fig. 1, RA-V) allows the entry of room air into the chamber but is closed during the induction of hypoxia.

These three valves are powered by an $\mathrm{AC}$ power source, connected through a custom-made relay termination panel (design can be supplied on request). The latter is connected via a 50-pin digital $\mathrm{I} / \mathrm{O}$ connectorribbon cable to an analogue/digital card (Analog Devices, Norwood, MA, USA) housed in a Pentium PC computer. The switch status and duration of $\mathrm{ON} / \mathrm{OFF}$ period of each valve is controlled via custom-made 
Fully-Automated Hypoxic Chamber

Fig. 2. Schematic representation of the duration of opening and closing the three solenoid valves used in the environmental system during two cycles of hypoxia, and their impact on internal oxygen concentration. Time, 12-min scale; B-valve, valve attached to the blower/suction motor; RA-valve. valve that controls entry of room air into the environmental chamber; $\mathrm{N}$ valve, valve that controls entry of $\mathrm{N}_{2}$ into the chamber; $\mathrm{O}_{2}, \mathrm{O}_{2}$ concentration inside the environmental chamber. Two cycles of hypoxia are shown. activated valves during cycle 1 ; 国, activated valves during cycle $2 ; \square$, deactivated valves. The RA-valve is open when deactivated. Numbers on $\mathrm{O}_{2}$ graph represent chamber $\mathrm{O}_{2}$ concentrations during different phases of the hypoxic cycle.
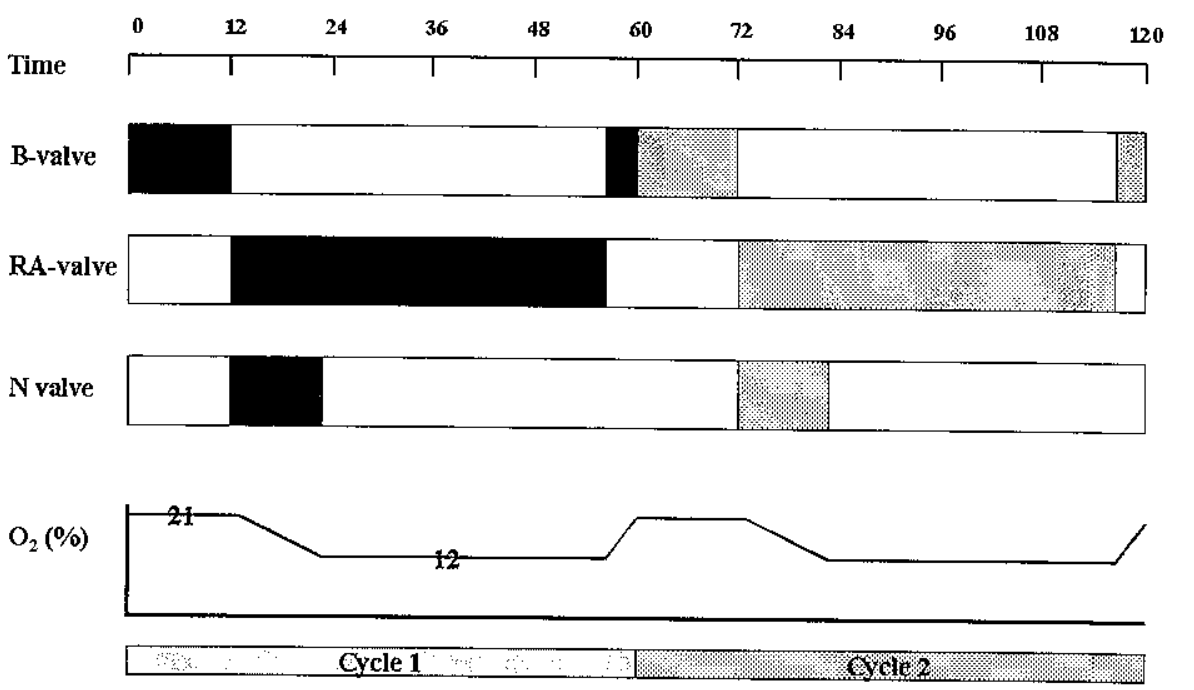

software (can be supplied on request) written using Microsoft ${ }^{\mathbb{B}}$ Visual Basic programming language.

This set-up allows the simultaneous exposure of four rabbits to repeated cycles of hypoxia over a period of $8-20 \mathrm{~h} / \mathrm{d}$ extending from a few days to months. The design and selection of the specific valves, as well as the computer hardware-software components, allows unattended operation over a period extending from 8 to $10 \mathrm{~h}$. A quick check-up is necessary at the end of such period to prevent $\mathrm{CO}_{2}$ accumulation in case of a power failure that might extend longer than $10 \mathrm{~h}$. In the case of power failure, all valves are set at resting conditions (N-V closed, B-V closed, RA-V open). This will allow room air to enter the box. While this will prevent $\mathrm{CO}_{2}$ narcosis or asphyxiation within the first few hours of power failure, circulation of air within the chamber will be very slow when the internal ventilation fan is not operational. As a result, $\mathrm{CO}_{2}$ concentration, temperature and humidity will ultimately rise after $10 \mathrm{~h}$, leading to distress of the animals.

Before any experiments, we first confirmed that the sound of opening and closing the valves did not affect the behavior of the animals. It is our experience that one of the best indicators of stress on animals in such environment is disturbance of the normal sleep/wake cycle and changes in food/water intake. To exclude such changes in our system, we monitored the food/water intake while the rabbits were housed in the environmental chamber. We also inspected and recorded the sleep/wake pattern during the same period. Our results showed that the sound of opening and closing the valves did not perturb either physiological process during normoxia.
We used our chamber for the simultaneous exposure of four rabbits to intermittent hypoxia during a period of $28 \mathrm{~d}$. For intermittent hypoxia, the cycle of hypoxia/normoxia lasted $1 \mathrm{~h}$ and was repeated continuously over $12 \mathrm{~h} / \mathrm{d}$. For this purpose, the following setup was used. The hypoxic cycle starts by activating the blower/suction motor and B-valve at the same time for $12 \mathrm{~min}$ while the RA-valve is turned off (chamber open to room air). The $\mathrm{N}$-valve is also turned off. This allows entry and circulation of room air into the chamber and maintenance of $\mathrm{O}_{2}$ at $21 \%$ (Fig. 2). When the motor and B-valve are turned off, the RAvalve and $\mathrm{N}$-valve are turned on simultaneously. This process separates the chamber from the outside environment and allows the flow of $\mathrm{N}_{2}$ into the chamber to induce hypoxia. During this period, the valve regulator/flow meter connected to the $\mathrm{N}_{2}$ cylinder is open allowing the gas to flow at a rate of $15 \mathrm{l} / \mathrm{min}$. This process results in a gradual fall in $\mathrm{O}_{2}$ concentration from 21 to $12 \%$ within $11 \mathrm{~min}$ (rate, $0.8 \% / \mathrm{min}$ ). At the end of this period, the $\mathrm{N}$-valve is turned off while the RA-valve remains activated (Fig. 2). The latter is finally turned off $34 \mathrm{~min}$ later while the blower/suction motor and B-valve are turned on for $3 \mathrm{~min}$ to the end of the first cycle (Fig. 2).

Our results showed that the concentration of $\mathrm{O}_{2}$ following the introduction of $\mathrm{N}_{2}$ inside the chamber and closure of the RA-valve remains stable at $12-13 \%$ over a period of $34 \mathrm{~min}$. In addition, once the blower and room air valves are activated, the $\mathrm{O}_{2}$ concentration increases rapidly within 3 min to $21 \%$ (Fig. 2).

In a group of four rabbits, arterial blood gases were measured serially during 12 -h cycles of hypoxia/room-air breathing described above (Fig. 3). For 


\section{CHAUFOUR et al.}

this purpose, a $3 \mathrm{Fr}$ catheter was inserted into the common carotid artery under anesthesia. The tube was tunneled under the skin and exited between the scapulae. Approximately $24 \mathrm{~h}$ later, the rabbits were housed in the chamber and the above cycles of intermittent hypoxia were set to run automatically over a period of $12 \mathrm{~h}$. Arterial blood samples were withdrawn repeatedly during exposure to hypoxic gas mixture and room-air breathing, while the animal remained in the chamber. Throughout the 12 -h test, chamber $\mathrm{CO}_{2}$ concentration was always $<1.0 \%$. The temperature at the beginning of the cycle was $24^{\circ} \mathrm{C}$ but increased to $26 \pm 0.5^{\circ} \mathrm{C}$ during hypoxia with the closure of the RA$\mathrm{V}$. In each cycle, the chamber $\mathrm{O}_{2}$ concentration varied from 21 to $12 \%$ as described above. During the period of hypoxic exposure, repeated analysis of arterial blood gases confirmed that hypoxia, with the associ-

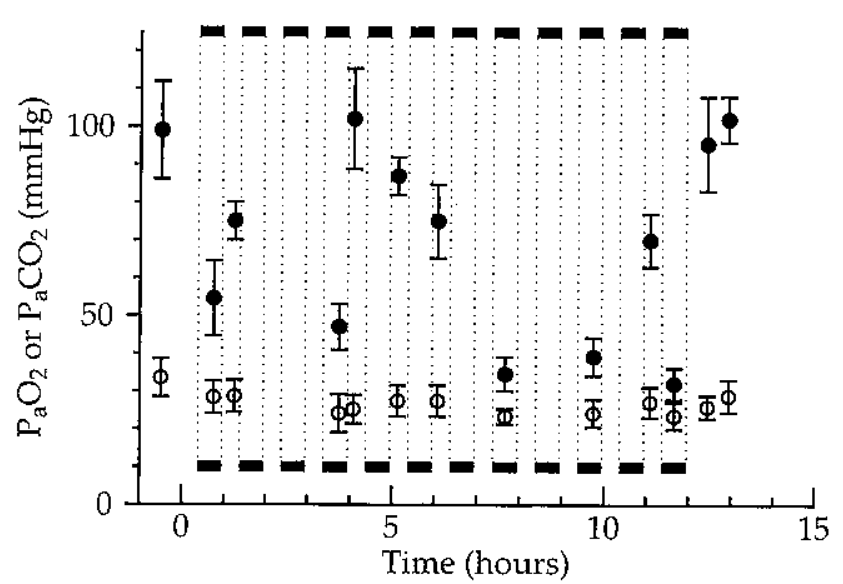

Fig. 3. Arterial $\mathrm{PO}_{2}$ and $\mathrm{PCO}_{2}$ during $12 \mathrm{~h}$ of intermittent hypoxia. Four rabbits were housed in the chamber and exposed to 12 cycles of hypoxia (areas within the dotted boxes) and room-air breathing (areas outside the dotted boxes). Data represent the mean \pm SEM. $-P a_{O_{2}} ; O$, $\mathrm{PaCO}_{2}$. Data at times less than zero represent the baseline measurements. Data after $12 \mathrm{~h}$ represent those of blood samples withdrawn at recovery 30 and $60 \mathrm{~min}$ after removal of the rabbit from the chamber. ated hypocapnia, mirrored changes in chamber $\mathrm{O}_{2}$ concentration. Thus, the mean $\mathrm{Pa}_{\mathrm{O}_{2}}$ was $41 \pm 3.0$ $\mathrm{mmHg}$ and $\mathrm{Pa}_{\mathrm{CO}_{2}}$ was $24 \pm 0.7 \mathrm{mmHg}$ ( \pm SEM) during hypoxic periods. Following termination of the study and exposure of the rabbits to room air, the mean $\mathrm{Pa}_{\mathrm{O}_{2}}$ and $\mathrm{Pa}_{\mathrm{CO}_{2}}$ recovered within $60 \mathrm{~min}$ to $96 \pm 4$ and $28 \pm$ $0.5 \mathrm{mmHg}$, respectively. Interestingly, while the rabbits were exposed to repeated cycles of hypoxemia/ hypocapnia, analysis of arterial blood gases showed the development of respiratory alkalosis (Table 1). This was associated, at approximately $9-10 \mathrm{~h}$ of hypoxic-induced hyperventilation, with renal compensation. Thus, in the initial few hours of repeated hypoxemia/hypocapnia, $\mathrm{pH}$ increased associated with a fall in bicarbonate. Persistent fall in $\mathrm{Pa}_{\mathrm{CO}_{2}}$ during intermittent hypoxemia was associated with a fall in renal bicarbonate reabsorption. This was evident by a gradual return of $\mathrm{pH}$ to normal at the later stages of the test in spite of the continued fall in bicarbonate. However, these changes were transient in nature, and acid-base balance returned to normal within a short period of time after termination of the experiment. During exposure to hypoxia, the animals did not seem to be distressed. They continued to consume the same amount of food and water as during baseline recording (outside the hypoxic chamber).

Using our system, different concentrations of $\mathrm{O}_{2}$ can be selected using different time intervals for the opening and closing of the valves. The only limiting factor in this process is the replacement of $\mathrm{N}_{2}$ cylinders. Using the above set-up, $165 \mathrm{l}$ of $\mathrm{N}_{2}$ are used per cycle of hypoxia (total duration: $60 \mathrm{~min}, \mathrm{O}_{2}$ concentration $12-13 \%$ ). This amounts to $2,000 l$ when the cycles of hypoxia/normoxia are run continuously over a period of $12 \mathrm{~h} / \mathrm{d}$. Thus, the large-size cylinder $(\mathrm{G}$ cylinder, approximate capacity $9,200 l$ ) needs to be changed every $4 \mathrm{~d}$ using our set-up. A shorter cycle of hypoxia/normoxia, or more severe levels of hypoxia, would consume different amounts of $\mathrm{N}_{2}$.

Table 1. Mean levels of bicarbonate, $\mathrm{pH}$, arterial $\mathrm{PO}_{2}$ and $P \mathrm{CO}_{2}$ during baseline, hypoxia and at recovery after $12 \mathrm{~h}$ of intermittent hypoxia.

\begin{tabular}{cccccc}
\hline Time $(\mathrm{min})$ & Cycle & {$\left[\mathrm{HCO}_{3}{ }^{-}\right](\mathrm{mmol} / \mathrm{l}$} & $\mathrm{pH}$ & $\mathrm{Pa}_{\mathrm{O}_{2}}(\mathrm{mmHg})$ & $\mathrm{Pa}$ \\
\hline Baseline $^{*}$ & - & $23.4 \pm 1.8$ & $7.45 \pm 0.07$ & $97 \pm 6$ & $34 \pm 5$ \\
45 & 1 & $21.8 \pm 2.1$ & $7.49 \pm 0.08$ & $65 \pm 10$ & $29 \pm 4$ \\
225 & 4 & $19.2 \pm 2.3$ & $7.51 \pm 0.10$ & $47 \pm 6$ & $24 \pm 5$ \\
460 & 7 & $18.8 \pm 2.0$ & $7.51 \pm 0.09$ & $35 \pm 9$ & $23 \pm 2$ \\
585 & 10 & $18.3 \pm 1.6$ & $7.49 \pm 0.08$ & $39 \pm 5$ & $24 \pm 4$ \\
700 & 12 & $17.7 \pm 1.5$ & $7.48 \pm 0.12$ & $32 \pm 4$ & $24 \pm 4$ \\
Control $^{* *}$ & - & $20.2 \pm 1.8$ & $7.45 \pm 0.7$ & $102 \pm 6$ & $29 \pm 4$ \\
\hline
\end{tabular}

* Measurements before placing the rabbit in the chamber. ** Measurements performed $1 \mathrm{~h}$ after recovery. All measurements were made during exposure to hypoxia within the indicated cycles. 
We have used this set-up for the simultaneous exposure of four rabbits to repetitive hypoxia $(12 \mathrm{~h} / \mathrm{d})$ over a period of $28 \mathrm{~d}$. The operator is required to check the environmental chamber once during $12 \mathrm{~h}$ of operation. In our experience of exposure of 12 rabbits to this process, no malfunction occurred during the operation of this automated system, and no loss of animals was reported. On one occasion, there was a brief power failure that resulted in a complete shutdown of the system. To circumvent any harm to the animals, an audio alarm could be included in the system to give early warning to the animal-care staff or the researcher. In our case, the power failure lasted only $45 \mathrm{~min}$, after which the computer restarted, and after loading the Windows operating system software, it automatically started our custom-software using the internally-stored parameters of open/close/delay times of each valve.

The automated system described in the present report allows the development of cyclical hypoxemia in four rabbits. The selection of the duration of activation-deactivation of each valve allowed operation of the system without using expensive equipment for analysis of $\mathrm{CO}_{2}-\mathrm{O}_{2}$ gas concentrations. However, the use of such instruments is necessary in the initial setup experiments to determine the duration of each component of the hypoxic cycle, as well as measure the concentration of $\mathrm{CO}_{2}$, humidity and temperature. Furthermore, while our automated system allows the development of hypoxemia, it does not control the level of arterial $\mathrm{PCO}_{2}$. The maintenance of $\mathrm{CO}_{2}$ at a eucapnic level would require the addition of another circuit to allow injection of $\mathrm{CO}_{2}$ gas in the system during hypoxia (due to hypoxic-induced hyperventilation and resultant hypocapnia). Furthermore, while the animals are housed in the environmental chamber, remote control monitoring systems (electrodes, probes, etc.) can be used to record physiological data, if necessary.
In conclusion, we have described a simple, cost-effective and fully-automated system that allows the simultaneous development of repeated cycles of hypoxemia in four medium-size animals over a period up to $12 \mathrm{~h} / \mathrm{d}$.

The authors appreciate the technical assistance of $\mathrm{Mr}$. Hans Henrichsen and Mr. Paul Wilkie in the design and construction of the chamber box.

\section{REFERENCES}

1. Beckman JS: The double-edged role of nitric oxide in brain function and superoxide-mediated injury. J Dev Physiol 15: 53-59, 1991

2. Cazevieille $C$, Muller $A$, Meynier $F$, and Bonne $C$ : Superoxide and nitric oxide cooperation in hypoxia/reoxy. genation-induced neuron injury. Free Radical Biol Med 14: 389-395, 1993

3. Moore-Gillon JC and Cameron IR: Right ventricular hypertrophy and polycythaemia in rats after intermittent exposure to hypoxia. Clin Sci 69: 595-599, 1985

4. Fletcher EC, Lesske J, Qian W, Miller CC III, and Unger $\mathrm{T}$ : Repetitive, episodic hypoxia causes diurnal elevation of blood pressure in rats [see comments]. Hypertension 19: 555-561, 1992

5. Pastoris O, Dossena M, Foppa P, Arnaboldi R, Gorini $A$, Villa RF, and Benzi $G$ : Modifications by chronic intermittent hypoxia and drug treatment on skeletal muscle metabolism. Neurochem Res 20: 143-150, 1995

6. Marzatico F, Curti D, Dagani F, Taglietti M, and Benzi G: Brain enzyme adaptation to mild normobaric intermittent hypoxia. J Neurosci Res 16: 419-428, 1986

7. Benzi G, Gorini A, Arnaboldi R, Ghigini B, and Villa R: Effect of intermittent mild hypoxia and drug treatment on synaptosomal nonmitochondrial ATPase activities. J Neurosci Res 34: 654-663, 1993

8. Gingras-Leatherman JL, MCNamara MC, and Lawson EE: Age-dependent influence of hypoxia on methionine-enkephalin concentration within rabbit brainstem nuclei. Pediatr Res 20: 655-657, 1986

9. Waters KA, Beardsmore CS, Paquette J, Turner GA, and Moss IR: Electrocorticographic activity during repeated vs continuous hypoxia in piglets. Brain Res Buil 41: 185-192, 1996 